\title{
Simple markers for subclinical inflammation in the different phases of bipolar affective disorder
}

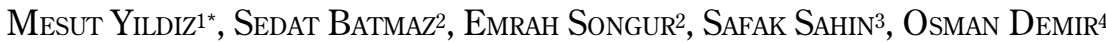 \\ 1 Department of Psychiatry, School of Medicine, Marmara University, Istanbul, Turkey. \\ 2 Department of Psychiatry, School of Medicine, Gaziosmanpasa University, Tokat, Turkey. \\ ${ }^{3}$ Department of Internal Medicine, School of Medicine, Gaziosmanpasa University, Tokat, Turkey. \\ ${ }^{4}$ Department of Biostatistics, School of Medicine, Gaziosmanpasa University, Tokat, Turkey. \\ * At Gaziosmanpașa University when the study was conducted. \\ The study was conducted in Gaziosmanpașa University School of Medicine, Turkey.
}

Received: 10/30/2016 - Accepted: 11/10/2016

DOl: 10.1590/0101-60830000000101

\begin{abstract}
Background: Recently, a growing number of publications have suggested that the immune-inflammatory system may be involved in the etiology of bipolar disorder (BD). Objective: The aim of this study was to investigate neutrophil-lymphocyte ratio (NLR), platelet-lymphocyte ratio (PLR), and red cell distribution width (RDW) in the three different phases of BD patients compared to each other and controls. Methods: One hundred eighty-seven bipolar patients (78 euthymic, $53 \mathrm{manic} /$ hypomanic and 56 depressed), and 62 age and sex matched controls were enrolled. Sociodemographic variables and complete blood count parameters of the patients and the control group were recorded. Results: The groups did not differ from each other on the hematological parameters, except for NLR and RDW. Post-hoc analyses revealed that NLR values were significantly higher in the euthymic and manic/hypomanic bipolar groups compared to control group. In addition, post-hoc analyses revealed that RDW values were significantly higher in the manic/hypomanic bipolar group relative to the control group. Discussion: Longitudinal studies evaluating the levels of inflammatory markers in the early phases of the disorder, and their relationship with the development of different episodes and medical comorbidities may be useful to understand the role of inflammation in BD.
\end{abstract}

Yildiz M et al. / Arch Clin Psychiatry. 2016;43(6):143-6

Keywords: Bipolar affective disorder, inflammation, neutrophil-lymphocyte ratio, platelet-lymphocyte ratio, red cell distribution width.

\section{Introduction}

Bipolar disorder (BD) is a chronic, relapsing illness characterized by recurrent episodes of manic or depressive symptoms, with intervening periods that are relatively symptom-free. The symptoms of bipolar disorder firstly appear in adolescence or early adulthood. Nevertheless onset in later life is also possible'. $\mathrm{BD}$ has two major types including BD type I and type II. The lifetime prevalence rates for $\mathrm{BD}$ are estimated at $1.0 \%$ for bipolar I disorder (BD-I), $1.1 \%$ for $\mathrm{BD}-\mathrm{II}$ and $2.4 \%$ for subthreshold $\mathrm{BD}$ $(4.4 \% \text { total })^{2}$. Bipolar disorder has a lifelong impact on patients' overall health status, quality of life, and functioning3. Although the etiology of bipolar disorder is not yet fully understood, it is thought that it is influenced by a combination of factors, including: genetics, biochemical, environmental, infections, immune system disturbances, and inflammatory processes ${ }^{4-9}$.

Inflammatory factors, also known as cytokines interact with the neurotransmitters and are associated with mood control, energy and activity $^{10}$. In the last years, a growing number of publications have suggested that the immune-inflammatory system may be involved in the etiology of BD?.

Mania is characterized by the increased levels of the soluble interleukin- 6 receptor (sIL-6R); sIL-2R, TNF- $\alpha$, CRP and immunoglobulin levels ${ }^{11,12}$. Conversely, some studies have found elevations in anti-inflammatory markers such as IL-4 among subjects with mania ${ }^{13,14}$. Bipolar depression, shows a similar immuneinflammatory profile as major depression and is characterized by increased IL-6, sIL-6R and sIL-2R levels ${ }^{15}$. While some studies have found cytokine abnormalities in euthymic bipolar patients ${ }^{16,17}$, other studies found no difference ${ }^{18,19}$. Additionally, recent research has demonstrated phasic differences in inflammatory markers such as relative increase in IL- $1 \beta$ and IL- 6 during depression versus mania and increased sIL-2R, IL- 4 and CRP during mania versus depression ${ }^{20}$. There are contradictory results in studies investigating immune-inflammatory markers in $\mathrm{BD}^{21}$.

The neutrophil-lymphocyte ratio (NLR), platelet-lymphocyte ratio (PLR) and red cell distribution width (RDW) may be indicators of systemic subclinical inflammation ${ }^{22,23}$. Numerous studies have examined the NLR in the context of inflammatory disease. NLR reflects the intensity of stress and systemic inflammation in critically ill patients. Increased NLR values have been reported to be a poor prognostic indicator in patients with several malignancies and coronary heart diseases ${ }^{24,25}$. Similarly PLR was demonstrated as a prognostic factor in patients with systemic diseases and cancer ${ }^{26,27}$. The red cell distribution width (RDW) has also been shown to be associated with systemic inflammatory conditions ${ }^{28}$.

To date, few studies have examined the NLR and PLR in psychiatric disorders. One study found increased NLR in schizophrenic subjects compared to controls ${ }^{29}$. Another study investigated the NLR and PLR ratios in manic and euthymic bipolar patients. Manic and euthymic $\mathrm{BD}$ subjects demonstrated an increase in both parameters compared to healthy controls ${ }^{30}$. Additionally, in another study, patients with BD showed increased NLR relative to controls ${ }^{31}$.

Our aim is to investigate the NLR, PLR and RDW in the three different phases of bipolar affective patients; euthymic, depressive, manic/hypomanic compared to each other and controls. We hypothesized that: I) NLR, PLR and RDW values should be higher in patients group as a whole relative to healthy controls. II) NLR, PLR and RDW levels of euthymic patients should be lower than active phases of the illness, namely manic/hypomanic and depressive phases. 


\section{Methods}

\section{Patients}

The data was derived from the clinical files of inpatients and outpatients with 'Bipolar Affective Disorder', who had been diagnosed with BD type 1 according to the criteria of the Diagnostic and Statistical Manual of Mental Disorders, Fourth Edition, Text Revision (DSM-IV, TR) ${ }^{32}$. The diagnoses were confirmed by two psychiatrists from the files of the patients. The eligible participants were physically healthy, and between the ages of 18-65 years. Patients were excluded from the study if they met one or more of the following criteria: comorbid hypertension, diabetes mellitus, hepatic or renal failure, obesity (BMI $>30 \mathrm{~kg} / \mathrm{m}^{2}$ ), heavy smoking, alcohol or substance abuse, manifest systemic disease, clinical evidence of an active infection, acute or chronic endocrinological, inflammatory or autoimmune diseases, malignant diseases, and treatment with anti-inflammatory or immunosuppressive medication. Between the period of April 2014 and July 2015, 519 files were screened. Three hundred and thirty two cases were excluded from the study due to the above criteria. As a consequence, 187 files of bipolar patients (78 euthymic, 53 manic/hypomanic and 56 depressed) were eligible for the study. Sixty-two age and sex matched controls were enrolled to the study. The same exclusion criteria were applied to the control group. Additionally, it was required not to have any psychiatric diagnoses according to their files. Sociodemographic variables and complete blood count $(\mathrm{CBC})$ parameters of the patients and the control group were recorded. The NLR and PLR were obtained from the laboratory records by the absolute neutrophil count divided by the absolute lymphocyte count, and by the platelet count divided by the absolute lymphocyte count, respectively. RDW values were obtained from the CBC results. The study was approved by Gaziosmanpaşa University Clinical Trials Ethics Committee, and complied with the Declaration of Helsinki.

\section{Statistical analysis}

The statistical analyses were performed using IBM SPSS for Windows, Version 22.0 (IBM Corp, 2013) Shapiro-Wilk test was used to determine whether the parameters were normally distributed, and Chi-squared test, one-way analysis of variance (ANOVA), followed by Scheffe post-hoc analysis, and KruskalWallis test, followed by Dunn - Bonferonni post-hoc analysis (Dunn, 1964) were used for group comparisons. The bipolar patient group as a whole was also compared with the healthy controls by Mann-Whitney U test. Statistical significance was set at a $p$ value $<0.05$.

\section{Results}

\section{Descriptive statistics}

A total of 78 euthymic ( $50 \%$ female; mean age $=42.29$ years, $S D$ $=11.85)$, 56 depressed $(42.9 \%$ female; mean age $=42.70$ years, $S D=11.71)$, and 53 hypomanic/manic $(50.9 \%$ female; mean age $=39.94$ years, $S D=12.21$ ) bipolar patients aged 18 and older, and 62 controls $(51.6 \%$ female; mean age $=41.63$ years, $S D=10.49)$ were recruited for the study. The bipolar groups and the healthy controls did not statistically differ from each other on neither $\left(\chi^{2}=1.126, p=0.771\right.$ for sex, and $F(3,245)=0.615, p=0.606$ for age $)$.

\section{Group comparisons}

The bipolar patient group as a whole statistically significantly differed from the healthy control only on three CBC parameters, i.e. neutrophil counts, red blood cell (RBC) counts, and NLR. Neutrophil counts in bipolar patients (Median $(\mathrm{Mdn})=4.58)$ was significantly higher in the patient group compared to the controls $(\mathrm{Mdn}=3.97), U=474, z=-2.147, p=0.032$. NLR ratio was also significantly higher in the patients compared to the controls (Mdn $=1.95$, and 1.66, respectively), $U=4794, z=-2.041, p=0.041$. However, RBC counts were significantly lower in the patient group compared to the controls ( $\mathrm{Mdn}=4.81$, and 5.02, respectively), $U=6879.5, z=2.203, p=0.028$.

The Shapiro-Wilk test revealed that except for the hemoglobin values, the variables were not normally distributed. Therefore, Kruskal-Wallis test was performed to compare the groups, except for the hemoglobin values. The bipolar groups separately and the control group did not differ from each other on the hematological parameters, except for the NLR and RDW. The results are summarized in Table 1.

Post-hoc analyses for the NLR revealed that the control group statistically significantly differed from the euthymic and manic/ hypomanic bipolar groups ( $p=0.025$ and $p=0.027$, respectively). NLR values were higher in euthymic and manic/hypomanic bipolar patients compared to controls. In addition, post-hoc analyses for RDW revealed that the control group statistically significantly differed from the manic/hypomanic bipolar group $(p=0.003)$. $\mathrm{RDW}$ values were higher in the manic/hypomanic group relative to controls.

\section{Discussion}

There has been growing interest in immune-inflammatory activity in bipolar affective disorder. In the present study, we aimed to investigate NLR, PLR and RDW values in different phases of

Table 1. Comparison of groups on hematological parameters

\begin{tabular}{|c|c|c|c|c|c|}
\hline & $\begin{array}{c}\text { Control Group Median } \\
(25-75 \%)\end{array}$ & $\begin{array}{c}\text { Euthymic Bipolar Group } \\
\text { Median } \\
(25-75 \%) \\
\end{array}$ & $\begin{array}{c}\text { Depressed Bipolar Group } \\
\text { Median } \\
(25-75 \%) \\
\end{array}$ & $\begin{array}{c}\text { Manic/Hypomanic Bipolar } \\
\text { Group Median } \\
(25-75 \%)\end{array}$ & $H$ \\
\hline WBC $\left(x 10^{3} / \mu L\right)$ & $6.9[6.03-8]$ & 7.19 [6.01-9.07] & 8.27 [6.27-10.08] & 7,54 [6.24-9.74] & 6.940 \\
\hline $\operatorname{NEU}\left(\times 10^{3} / \mu \mathrm{L}\right)$ & 3.97 [3.4-4.69] & 4.29 [3.33-5.76] & $4.79[3.32-6]$ & 4.65 [3.47-5.87] & 5.133 \\
\hline LYM (x103//LL) & 2.31 [1.96-2.75] & 2.16 [1.64-2.68] & $2.46[1.77-3.41]$ & 2.26 [1.94-2.78] & 5.580 \\
\hline $\mathrm{RBC}(\mathrm{x} 106 / \mu \mathrm{L})$ & $5.02[4.66-5.3]$ & $4.9[4.52-5.21]$ & $4.74[4.53-5.1]$ & $4.82[4.47-5.37]$ & 5.862 \\
\hline $\mathrm{HGB}^{*}(\mathrm{~g} / \mathrm{dL})$ & $13.99[13.54-14.45]$ & 13.53 [13.15-13.91] & $14.16[13.77-14.54]$ & 13.93 [13.38-14.49] & 1.625 \\
\hline RDW \% & 14.3 [11.78-15.8] & 15.05 [12.65-16.2] & 14.05 [11.85-15.7] & 13.09 [11.47-15.2] & $9.508^{* *}$ \\
\hline 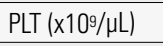 & 248.45 [212.5-284.5] & 232.8 [189-290] & 251.75 [195-308.9] & 227.1 [184-275.7] & 2.442 \\
\hline MPV (fL) & 8.2 [7.22-9.33] & 7.68 [6.93-8.71] & $8.22[7.02-9.1]$ & 7.99 [7.01-8.64] & 2.976 \\
\hline PDW \% & 19.05 [17.7-20.66] & $18.3[17.4-19.86]$ & $18.7[17.3-20.21]$ & 19.1 [18.3-19.8] & 4.091 \\
\hline NLR & $1.66[1.4-2.09]$ & 1.99 [1.42-3.24] & $1.7[1.24-2.52]$ & 2.28 [1.44-3.03] & $8.163^{* *}$ \\
\hline PLR & 105.12 [86.5-128.85] & 113.52 [81.67-152.35] & 91.11 [71.57-134.14] & 101.57 [75.39-140.58] & 4.527 \\
\hline
\end{tabular}

*ANOVA [Mean (95\% Confidence interval)]; ${ }^{* *} p<0.05$. 
bipolar affective disorder retrospectively. It was demonstrated that NLR was higher in both euthymic and manic/hypomanic bipolar patients compared to controls. Additionally, RDW was found to be higher in hypomanic/manic group relative to controls. However, there was not a significant difference in PLR values between patient groups and controls.

Result of the studies investigating immune-inflammatory markers in bipolar disorder are controversial ${ }^{21}$. Additionally, results may vary according to different stages of bipolar disorder ${ }^{14}$.

In the present study, NLR and RDW but not PLR was found to be increased in manic/hypomanic patients compared to controls. Mania has been reported to be associated with increased levels of soluble interleukin-6 receptor (sIL-6R), sIL-2R, positive acute-phase proteins, immunoglobulins, and complement factors (C3 and C6) ${ }^{12}$. Our finding is in line with Kalelioğlu et al. study in terms of NLR ${ }^{30}$. Nevertheless, we did not find a difference with regard to PLR in manic/hypomanic patients relative to controls. Some researchers found NLR as a more reliable marker for subclinical inflammation when compared to PLR ${ }^{33}$. The difference in results between our study and Kalelioğlu's study might be associated with this.

In a similar way, NLR was elevated in euthymic patients relative to control subjects. This result is consistent with Kalelioğlu et al's study. Although cytokine abnormalities has been shown in euthymic patients in a number of studies ${ }^{16,17}$, some studies found no difference between euthymic and control subjects ${ }^{18,19}$.

An interesting finding of the present study is that, unlike euthymic and manic/hypomanic patients there was no difference between depressed patients and controls in terms of NLR. This result can be associated with the sample size of our study. Additionally, it was suggested that lower levels of inflammatory markers among bipolar depressed subjects relative to manic subjects may be a result of detection limit. In other words; bipolar depressed patients may be different from controls with regard to NLR, but we can not measure it due to detection limits in current laboratory techniques ${ }^{34}$. It is also possible that the vast majority of the inflammation observed in bipolar disorder occurs in manic phase and the degree of inflammation may be lower in the depressed state. Last, as catecholamine neurotransmission is found to be high in mania and low in depression; low levels of inflammatory markers seen in bipolar depressed patients may be associated with this ${ }^{35}$.

This is the first study examining NLR, PLR and RDW as inflammatory markers in different phases of bipolar affective disorder. Limitations of the present study are as follows: First, while investigating the different phases of $\mathrm{BD}$, we had different patient populations. Measuring the inflammatory markers in the different phases of the disorder in the same patient, i.e. an intra-individual study design, may show more reliable results. Second, we could not include possible confounding clinical variables such as duration of the disorder and number of episodes due to the missing data in some patients. It is well-known that proinflammatory state may differ according to the onset age of illness and number of episodes the patient experienced ${ }^{11}$. Third, although we excluded patients with systemic inflammatory conditions rigorously according to their files, it must be kept in mind that undiagnosed comorbidities or confounding factors might have as well influenced our results. Last, we did not control for the medications the patients used. Medications used in the treatment of BD have been reported to exert anti-inflammatory effects ${ }^{36}$.

As a result, it may be suggested that inflammatory markers as measured by NLR and RDW present phasic differences in bipolar disorder. Longitudinal studies evaluating the levels of inflammatory markers in the early onset of illness and their relationship with the development of different episodes and medical comorbidities may be useful to understand the role of inflammation in $\mathrm{BD}$.

\section{Disclosure of interest}

None to declare.

\section{Acknowledgements}

This paper was entirely funded by authors and no pharmaceutical companies were informed of, or had any involvement in the paper. All authors have contributed to this paper.

\section{References}

1. Merikangas KR, Akiskal HS, Angst J, Greenberg PE, Hirschfeld RM, Petukhova M, et al. Lifetime and 12-month prevalence of bipolar spectrum disorder in the National Comorbidity Survey replication. Arch Gen Psychiatry. 2007 May;64(5):543-52. Erratum in: Arch Gen Psychiatry. 2007;64:1039.

2. Kessler RC, Merikangas KR, Wang PS. Prevalence, comorbidity, and service utilization for mood disorders in the United States at the beginning of the twenty-first century. Annu Rev Clin Psychol. 2007;3:137-58.

3. Geddes JR, Miklowitz DJ. Treatment of bipolar disorder. Lancet. 2013;381(9878):1672-82.

4. Craddock N, Sklar P. Genetics of bipolar disorder. Lancet. 2013;381(9878):1654-62.

5. Falkai P, Malchow B, Schmitt A. Neurobiological background of affective disorders. In: Dieter Schoepf, editor. Psychiatric Disorders-New Frontiers in Affective Disorders, Intech 2013, p. 3-20.

6. Koenders MA, Giltay EJ, Spijker AT, Hoencamp E, Spinhoven P, Elzinga BM. Stressful life events in bipolar I and II disorder: cause or consequence of mood symptoms? J Affect Disord. 2014;161:55-64.

7. Mortensen PB, Pedersen CB, McGrath JJ, Hougaard DM, NørgaardPetersen B, Mors $\mathrm{O}$, et al. Neonatal antibodies to infectious agents and risk of bipolar disorder: a population-based case-control study. Bipolar Disord. 2011;13(7-8):624-9.

8. Tsai SY, Chung KH, Wu JY, Kuo CJ, Lee HC, Huang SH. Inflammatory markers and their relationships with leptin and insulin from acute mania to full remission in bipolar disorder. J Affect Disord. 2012;136(1-2):110-6.

9. Leboyer M, Soreca I, Scott J, Frye M, Henry C, Tamouza R, et al. Can bipolar disorder be viewed as a multi-system inflammatory disease?. J Affect Disord. 2012;141(1):1-10.

10. Brietzke E, Kapczinski F. TNF-alpha as a molecular target in bipolar disorder. Prog Prog Neuropsychopharmacol Biol Psychiatry. 2008;32(6):1355-61.

11. Goldstein BI, Kemp DE, Soczynska JK, McIntyre RS. Inflammation and the phenomenology, pathophysiology, comorbidity, and treatment of bipolar disorder: a systematic review of the literature. J Clin Psychiatry. 2009;70(8):1078-90.

12. Anderson G, Maes M. Bipolar disorder: role of immune-inflammatory cytokines, oxidative and nitrosative stress and tryptophan catabolites. Curr Psychiatry Rep. 2015;17(2):8.

13. Kim YK, Myint AM, Lee BH, Han CS, Lee SW, Leonard BE, et al. T-helper types 1, 2, and 3 cytokine interactions in symptomatic manic patients. Psychiatry Res. 2004;129(3):267-72.

14. Ortiz-Domínguez A, Hernández ME, Berlanga C, Gutiérrez-Mora D, Moreno J, Heinze G, et al. Immune variations in bipolar disorder: phasic differences. Bipolar Disord. 2007;9(6):596-602.

15. Maes M, Meltzer HY, Bosmans E, Bergmans R, Vandoolaeghe E, Ranjan $\mathrm{R}$, et al. Increased plasma concentrations of interleukin-6, soluble interleukin-6, soluble interleukin-2 and transferrin receptor in major depression. J Affect Disord. 1995;34(4):301-9.

16. Breunis MN, Kupka RW, Nolen WA, Suppes T, Denicoff KD, Leverich GS, et al. High numbers of circulating activated T cells and raised levels of serum IL-2 receptor in bipolar disorder. Biol Psychiatry. 2003;53(2):157-65

17. Barbosa IG, Rocha NP, Bauer ME, de Miranda AS, Huguet RB, Reis HJ, et al. Chemokines in bipolar disorder: trait or state?. Eur Arch Psychiatry Clin Neurosci. 2013;263(2):159-65.

18. Guloksuz S, Cetin EA, Cetin T, Deniz G, Oral ET, Nutt DJ. Cytokine levels in euthymic bipolar patients. J Affect Disord. 2010;126(3):458-62.

19. Remlinger-Molenda A, Wojciak P, Michalak M, Karczewski J, Rybakowski JK. Selected cytokine profiles during remission in bipolar patients. Neuropsychobiology. 2012;66(3):193-8.

20. Modabbernia A, Taslimi S, Brietzke E, Ashrafi M. Cytokine alterations in bipolar disorder: a meta-analysis of 30 studies. Biol Psychiatry. 2013;74(1):15-25. 
21. Barbosa IG, Machado-Vieira R, Soares JC, Teixeira AL. The immunology of bipolar disorder. Neuroimmunomodulation. 2014;21(2-3):117-22.

22. Akbas EM, Demirtas L, Ozcicek A, Timuroglu A, Bakirci EM, Hamur H, et al. Association of epicardial adipose tissue, neutrophil-to-lymphocyte ratio and platelet-to-lymphocyte ratio with diabetic nephropathy. Int J Clin Exp Med. 2014;7(7):1794-801.

23. Hu ZD, Chen Y, Zhang L, Sun Y, Huang YL, Wang QQ, et al. Red blood cell distribution width is a potential index to assess the disease activity of systemic lupus erythematosus. Clin Chim Acta. 2013;425:202-5.

24. Walsh SR, Cook EJ, Goulder F, Justin TA, Keeling NJ. Neutrophillymphocyte ratio as a prognostic factor in colorectal cancer. J Surg Oncol. 2005;91(3):181-4.

25. Arbel Y, Finkelstein A, Halkin A, Birati EY, Revivo M, Zuzut M, et al. Neutrophil/lymphocyte ratio is related to the severity of coronary artery disease and clinical outcome in patients undergoing angiography. Atherosclerosis. 2012;225(2):456-60.

26. Turkmen K, Erdur FM, Ozcicek F, Ozcicek A, Akbas EM, Ozbicer A, et al. Platelet-to-lymphocyte ratio better predicts inflammation than neutrophil-to-lymphocyte ratio in end-stage renal disease patients. Hemodial Int. 2013;17(3):391-6.

27. Raungkaewmanee $S$, Tangjitgamol S, Manusirivithaya S, Srijaipracharoen S, Thavaramara T. Platelet to lymphocyte ratio as a prognostic factor for epithelial ovarian cancer. J Gynecol Oncol. 2012;23(4):265-73.

28. Horne BD, Muhlestein JB, Bennett ST, Anderson JL. The red cell distribution width predicts mortality among patients free from systemic inflammation. Circulation. 2014;130(Suppl 2):A14819.
29. Semiz M, Yildirim O, Canan F, Demir S, Hasbek E, Tuman TC et al. Elevated neutrophil/lymphocyte ratio in patients with schizophrenia. Psychiatr Danub. 2014;26(3):220-5.

30. Kalelioğlu T, Akkus M, Karamustafalioglu N, Genc A, Genc ES, Cansiz A, et al. Neutrophil-lymphocyte and platelet-lymphocyte ratios as inflammation markers for bipolar disorder. Psychiatry Res. 2015;228(3):925-7.

31. Çakır U, Tuman TC, Yıldırım O. Increased neutrophil/lymphoctye ratio in patients with bipolar disorder: a preliminary study. Psychiatr Danub. 2015;27(2):180-4.

32. American Psychiatric Association. Diagnostic and Statistical Manual of Mental Disorders. 4th ed., text rev. Washington, DC: Author; 2000.

33. Özer S, Yılmaz R, Sönmezgöz E, Karaaslan E, Taşkın S, Bütün İ, et al. Simple markers for subclinical inflammation in patients with Familial Mediterranean Fever. Med Sci Monit. 2015;21:298-303.

34. Russell A, Pariente CM, Mondelli V. Immune mechanisms and inflammation and their treatment impact. In: Yildiz A, Nemeroff C, Ruiz P, editors. The Bipolar Book, Oxford University Press; 2015.

35. Hope S, Dieset I, Agartz I, Steen NE, Ueland T, Melle I, et al. Affective symptoms are associated with markers of inflammation and immune activation in bipolar disorders but not in schizophrenia. J Psychiatr Res. 2011;45(12):1608-16.

36. Berk M, Kapczinski F, Andreazza AC, Dean OM, Giorlando F, Maes M, et al. Pathways underlying neuroprogression in bipolar disorder: focus on inflammation, oxidative stress and neurotrophic factors. Neurosci Biobehav Rev. 2011;35(3):804-17. 